\title{
EXPOSURE TO ENDOCRINE DISPERSERS AND XENOESTROGEN IN THE DEVELOPMENT OF BREAST CANCER: A LITERATURE REVIEW
}

Felipe Z. Pereira1, André G. Araújo', Bráulio B. Brandão1, Lucas C. Silva1', Larissa Amorim¹, Leonardo Queiroz, Felipe S. Rodrigues ${ }^{1}$, Fabiane A. Carvalho'

${ }^{1}$ Centro Universitário de Anápolis - UniEVANGÉLICA - Anápolis (GO), Brazil.

Objectives: To discuss the impact of endocrine disruptors (ED) on the human organism and the role of xenoestrogens in the development of breast cancer. Methodology: This is a qualitative literature review using PubMed, SciELO, and LILACS articles, in English, Spanish, and Portuguese, from 2014 to 2019. Case-control, sectional, and cohort studies of a total of 31 were included. Results: Xenoestrogens, disseminated by plastics, water, and food, are potentially harmful to women's homeostasis. They generate mutations and free radicals that cause DNA damage, increased phosphorylation of protein kinases, and activation of transcription factors, such as AP-1, NRF1, E2F, and CREB, bases of cancer by estrogens. They have been accused as potent mitogens, progressing the cycle from G1 to S phase, destabilizing DNA, and decreasing apoptosis. Bisphenol A (BPA) is one of the leading ED related to breast cancer. It is an estrogen receptor agonist (ER) and is hypothesized to be proinflammatory, stimulate cells via activation of iRhoms / ADAM17 or ADAM / 10, and induce expression of HOTAIR in breast cancer cells (MCF-7). There are several studies on the mechanisms by which neoplastic mammary cells overexpress ER- $\alpha 36$, as it induces drug resistance in treatment and mediates xenoestrogens, inducing different responses in other ER. Although carcinogenic, there are EDs with effects on the reduction of T-cell and B-cell lymphomas in experimental analyzes. Some of the phytoestrogens class are agonists and inhibit the proteasome, which can prevent ER + neoplasms. Conclusions: Human bioaccumulation by xenoestrogens causes changes in physiological, hormonal processes, and corroborates the tumor genesis, among them breast cancer. However, some may perform anticarcinogenic actions. Given the above, it is fundamental that new studies are carried out in order to clarify in more detail the deleterious effects and eventual benefits of EDs, to stimulate the prevention and / or correct use of them. 